\title{
Evaluation of binocular function among pre- and early-presbyopes with asthenopia
}

This article was published in the following Dove Press journal:

Clinical Optometry

\author{
William Reindel' \\ Lening Zhang' \\ Joseph Chinn² \\ Marjorie Rah' \\ 'Vision Care, Bausch \& Lomb Inc, \\ Rochester, NY, ${ }^{2} \mathrm{C}$ Chinn LLC, Lafayette, \\ CO, USA
}

Purpose: Individuals approaching presbyopia may exhibit ocular symptoms as they contend with visual demands of near work, coupled with natural age-related changes in accommodation. Therefore, accommodation and vergence of 30- to 40-year-old, myopic, soft contact lens wearing subjects with symptoms of asthenopia and no history of using multifocal lenses were evaluated. Patients and methods: In this prospective, observational study, 253 subjects with asthenopia were evaluated by 25 qualified practitioners, each at a different clinical site. Subjects were 30-40 years in age, had symptoms of soreness, eyestrain, tired eyes, or headaches with near work, regularly performed 2-3 consecutive hours of near work, and were undiagnosed with presbyopia. Amplitude of accommodation (AC) and near point convergence (NPC) were measured with a Royal Air Force binocular gauge. Triplicate push up and push down AC and NPC measures were recorded, and average AC values were compared to those calculated using the Hofstetter formula (HF).

Results: The average AC push up/push down value was significantly better than the HF prediction for this age range $(8.04 \pm 3.09$ vs $6.23 \pm 0.80 \mathrm{D})$, although $22.5 \%$ of subjects had mean AC below their HF value (5.36 $\pm 0.99 \mathrm{D})$. The average NPC push up/push down value was $12.0 \pm 4.69$ $\mathrm{cm}$. The mean binocular $\mathrm{AC}$ value using the push up measure was significantly better than the push down measure $(8.5 \pm 3.4$ vs $7.6 \pm 3.0 \mathrm{D})$. The mean NPC value using the push up measure was significantly worse than the push down measure $(13.0 \pm 5.0 \mathrm{vs} 11.0 \pm 4.7 \mathrm{~cm})$. The most frequent primary diagnosis was ill-sustained accommodation (54\%), followed by accommodative insufficiency (18\%), and accommodative infacility (12\%).

Conclusion: Based upon a standardized assessment of accommodation and vergence, illsustained accommodation was the most frequent diagnosis among this population.

Keywords: eyestrain, myopia, accommodation, vergence, lag, spherical aberration

\section{Introduction}

The digital world has rapidly expanded beyond the desktop computer. In 2015, the Pew Research Center (Washington, DC) reported that nearly two-thirds of Americans owned a smartphone, compared with approximately one-third in $2011 .{ }^{1}$ With increased use of digital media and decreased digital screen size, the demands on the binocular visual system have also increased. In 2016, almost 90\% of Americans were estimated to use digital devices for $\geq 2$ hours each day, and almost $60 \%$ for $\geq 5$ hours each day. ${ }^{2}$ Further, $65 \%$ reported experiencing symptoms of digital eyestrain, and $77 \%$ of those individuals reported using two or more devices simultaneously. Thirty-two percent of the population in the age range of 35-50 years spends at least 9 hours on digital devices each day, and $63 \%$ report symptoms of digital eyestrain. ${ }^{3}$
Correspondence: Marjorie Rah

Vision Care, Bausch \& Lomb Inc, I 400

North Goodman St, Rochester, NY

14609, USA

Tel +I 5854136397

Email Marjorie.rah@bausch.com 
The term digital eyestrain describes physical discomfort felt after $\geq 2$ hours in front of digital screens at close to midrange distance and is characterized by symptoms including neck/shoulder/back pain, eyestrain, headache, blurred vision, and dry eyes. ${ }^{3}$ However, ocular symptoms such as eyestrain, tired eyes, irritation, redness, blurred vision, and double vision, as well as headaches were reported associated with the use of computers at the end of the last century when computers became standard in the workplace. ${ }^{4-6}$ This set of symptoms came to be known as "computer vision syndrome" (CVS). ${ }^{7-12}$ The similarity in symptoms suggests that digital eyestrain and CVS are related if not the same, with the one important difference that digital devices are typically viewed at closer distance than are computer monitors.

Recent studies have identified mechanisms contributing to CVS as decreased blink frequency and blink amplitude, increased tear evaporation rate, and decreased tear film stability. ${ }^{13,14}$ One important aspect of CVS is the reduction in blink rate under conditions of sustained concentration. ${ }^{15}$ For example, blink rate in normal, non-lens wearing subjects decreased from nominal 17 blinks per minute at rest down to 4.5 blinks per minute when reading, ${ }^{16}$ and from $18 \pm 5.7$ down to $3.6 \pm 1.8$ blinks per minute during video display viewing. ${ }^{6}$ This phenomenon is especially significant for contact lens wearers because the resultant tear film disruption leads to visual aberration, due to both altered light refraction through the lens and lens dehydration that in itself alters lens geometry. ${ }^{17}$ Not surprisingly, the incidence of CVS is greater in lens wearers, especially after 6 hours of computer use. ${ }^{18}$ The use of other digital technologies with flat-panel displays such as cell phones, tablets, and e-readers is likewise associated with the symptoms of CVS. ${ }^{3,19}$

While blink activity contributes to digital eyestrain, prolonged exposure to near objects challenges the accommodative convergence system. ${ }^{10,20}$ Further, the accommodative system has been known to decline with age for at least a century and a half. ${ }^{21}$ Well before the introduction of the first personal computer, Hofstetter published his eponymous formula to calculate the mean, minimum, and maximum amplitude of accommodation (AC) for different age groups, ${ }^{22}$ based upon his analysis of normal $\mathrm{AC}$ values that others published previously, in 1864 (130 subjects, $10-80$ years of age $)^{21}$ and 1912 (4,200 subjects, 8-72 years of age). ${ }^{23}$ With increased age, the interval between 35 and 44 years has been described as the incipient phase of presbyopia, in which the $\mathrm{AC}$ becomes progressively reduced and leads to the eventual need for near addition interventions. ${ }^{24}$ The lack of near addition correction among patients in the early stages of presbyopia was found to be a risk factor for ocular complaints among those with longer daily durations of demanding computer work. ${ }^{25}$

The interaction between accommodation and vergence is also challenged during this age. ${ }^{26}$ Similar to age-related changes in $\mathrm{AC}$, heterophoria and fixation disparity are reported to increase with age (in the exo direction). ${ }^{27}$ In a population of 2,433 individuals ranging from 10 to 86 years of age, near point convergence (NPC) increased with age over the entire range of the population studied, the sharpest changes occurring between the 30 to 39 -year-old and the 40 to 49 -year-old age old groups. ${ }^{28}$ While not intending to evaluate the effect of age, Siderov et al nonetheless measured and compared NPC of non-presbyopic and presbyopic subjects and found $2 \times$ greater NPC in the latter group. ${ }^{29}$ They also speculated that differences between NPC (break) and NPC (recovery) in presbyopes may reflect age-related differences in vergence dynamics. Spierer and Hefetz followed 100 individuals over a 20 -year period and found an increase in NPC as subjects became pre-presbyopic (as they reached 34-38 years of age). ${ }^{30}$

Accommodative and vergence dysfunctions are a diverse group of anomalies that have a similar symptomatic profile to those reported as digital eyestrain. Common symptoms associated with accommodative and vergence anomalies include blurred vision, headache, ocular discomfort, ocular or systemic fatigue, diplopia, motion sickness, and loss of concentration while performing a task. ${ }^{31}$ Individuals approaching presbyopia may exhibit ocular symptoms as they contend with the visual demands of digital device viewing and other near work, coupled with natural age-related changes in accommodation. The exact cause of these symptoms is not well understood.

The objectives of this prospective, single-arm, observational study were first to evaluate and characterize the accommodation and vergence of a large population of 30 to 40-year-old myopic subjects who both used technology or performed other near-work tasks and reported symptoms of asthenopia (including burning, irritated, tearing, red, dry, and tired eyes, blurred vision and double vision, as well as sore or aching eyes, eye fatigue, muscle stress inside the eye, muscle stress around the eye, and headache) with no history of using multifocal lenses, and second to compare the measured accommodation values to those predicted by the Hofstetter formula (HF) proposed over a half century ago. ${ }^{22}$ As little such data appear in published literature, especially in the current age of digital devices, the results obtained with this relatively large population across multiple investigation centers provide insight into the relationships between age, CVS, and accommodative dysfunction. 


\section{Materials and methods}

This study was reviewed and approved by Southwest Independent Institutional Review Board (Fort Worth, TX, USA). Written approval of the protocol, informed consent form, and subject instructions were provided prior to initiation of the study. Eligible subjects gave written informed consent and complied with the study procedures.

\section{Study design and population}

Pre- and early-presbyopic, soft contact lens wearing subjects who reported symptoms of asthenopia were recruited and evaluated in this prospective study conducted in the United States. Twenty-five investigators, each at a different clinical site, enrolled a total of 253 subjects in the study. Eligible male and female subjects, 30-40 years of age, were myopic soft contact lens wearers with clear central corneas free from anterior segment disorders. All regularly performed at least one of the following activities daily for 2-3 hours without a break: computer use, cell phone use for games, maps, or Internet search, other handheld device use, reading, or hobbies that require midrange or close-up vision. In addition, all subjects experienced at least one of the following, four times a week as a result of these activities: eyestrain, tired eyes, headaches with near work, or soreness, ache, or pain inside the eyes. Individuals who required monovision, multifocal, or toric contact lenses or who had been diagnosed with presbyopia were not eligible to participate.

\section{Outcomes evaluated}

All testing was conducted with subjects using their habitual soft contact lenses. To ensure uniform testing, all study site investigators were trained on the use of the study instruments using the same standard clinical protocol. AC and NPC were measured with a Royal Air Force (RAF) binocular gauge. The RAF gauge and a metronome were used to regulate movement of the target. The box was moved slowly toward the subject at a rate of $\sim 2 \mathrm{~cm}$ per second. Three push up and push down $\mathrm{AC}$ and NPC measures were recorded in triplicate (three measurements in each eye for each of the measures), and average $\mathrm{AC}$ values were compared to those predicted by the $\mathrm{HF}^{22}$ Near heterophoria was measured by Maddox Wing test, which was selected because it is repeatable across study sites. Investigators diagnosed primary accommodation/vergence dysfunction using the Optometric Clinical Practice Guidelines of the American Optometric Association ${ }^{31}$ (Table 1).

\section{Statistical analysis}

All statistical analyses were conducted using the SAS statistical analysis package (version 9.1; SAS Institute Inc, Cary, NC, USA). All continuous variables are summarized as means and standard deviations. AC push up/push down measurements were compared to the Hofstetter predicted values using Student's $t$-test. Paired $t$-test was employed to compare the push up values against push down values from the same subjects for AC and NPC, respectively. Two-tailed tests were used for all comparisons. $p$-values $<0.05$ were designated statistically significant.

\section{Results}

Twenty-five investigators enrolled a total of 253 subjects in the study. The average subject age was $35.0 \pm 3.2$ years (mean \pm standard deviation). The subjects ranged in age from 30 to 40 years, with a median age of 35.0 years. Of the 253 subjects enrolled, $79.6 \%$ were female and $20.4 \%$ male; $80.8 \%$ were Caucasian, 10.9\% Black/African-American, 6.8\% Asian, $0.8 \%$ American Indian/Alaskan Native, and $0.8 \%$ other. All recruited subjects were adapted, soft contact lens wearers. The predominance of females in the study population did not occur by design but rather likely reflects the greater number of female than male contact lens wearers in the United States. The mean refraction sphere was $-3.27 \pm 1.6 \mathrm{D}$, with a range from -0.25 to $-7.00 \mathrm{D}$. The mean refraction cylinder was $-0.35 \pm 0.28 \mathrm{D}$, with a range from 0.00 to $-1.00 \mathrm{D}$.

The average AC push up/push down value $(8.04 \pm 3.09 \mathrm{D})$ was significantly better than what the HF would predict for this age range $(6.23 \pm 0.80 \mathrm{D}, p<0.0001$, Table 2$)$. However,

Table I Summary of accommodation/vergence dysfunction classifications and descriptions

\begin{tabular}{ll}
\hline Diagnosis & Description \\
\hline Accommodative insufficiency & Amplitude of accommodation is lower than expected for the patient's age. \\
Ill-sustained accommodation & Amplitude of accommodation is normal, but fatigue occurs with repeated accommodative stimulation. \\
Accommodative infacility & $\begin{array}{l}\text { Accommodative system is slow in making a change, or when there is considerable lag between the } \\
\text { stimulus to accommodation. }\end{array}$ \\
Convergence insufficiency & Deficiency of fusional convergence relative to the demand. \\
Convergence excess & Near deviation significantly more esophoric than distance deviation. \\
Other &
\end{tabular}

Note: Data from Cooper et al. ${ }^{31}$ 
67 of the 253 subjects (26.5\%) had AC below their predicted HF values with their habitual lenses. The mean AC push up/


The mean binocular $\mathrm{AC}$ value using the push up measure $(8.5 \pm 3.4 \mathrm{D})$ was significantly better than the push down measure (7.6 $\pm 3.0 \mathrm{D}, p<0.0001$, Table 3 ).

The average NPC push up/push down value was $12.0 \pm 4.69 \mathrm{~cm}$. The mean NPC value using the push up measure $(13.0 \pm 5.0 \mathrm{~cm})$ was significantly worse than the push down measure $(11.0 \pm 4.7 \mathrm{~cm}, p<0.0001$, Table 3). Among subjects with horizontal $(n=209)$ and vertical $(n=20)$ near phorias, the means were $0.92 \pm 3.16 \mathrm{D}$ for exophoria and $0.60 \pm 1.35 \mathrm{D}$ for right hyperphoria, respectively (Table 4).

The most frequent investigators-diagnosed primary accommodation/vergence dysfunction diagnosis for asthenopic symptoms was ill-sustained accommodation (54\%), followed by accommodative insufficiency (18\%), and accommodative infacility (12\%) (Figure 1). Convergence insufficiency $(6 \%)$ and excess $(5 \%)$ were less frequent.

\section{Discussion}

Accommodative function begins to decline as early as age 10 and continues to decline with age. ${ }^{32}$ This may be related to ocular symptoms such as eyestrain, tired eyes, irritation, redness, blurred vision, double vision, and headaches that

Table 2 Average amplitude of accommodation compared to predicted values from Hofstetter formula

\begin{tabular}{llll}
\hline Variable & Mean (D) & SD & p-value \\
\hline Average of AC push up/push down & 8.04 & 3.09 & $<0.0001$ \\
Predicted values from Hofstetter formula & 6.23 & 0.80 & \\
\hline
\end{tabular}

Abbreviations: AC, amplitude of accommodation; D, diopters; SD, standard deviation.

Table 3 Comparison of average push up and push down values for AC and NPC

\begin{tabular}{lllllll}
\hline Variable & \multicolumn{2}{l}{ Push up (D) } & & \multicolumn{2}{l}{ Push down (D) } & p-value \\
\cline { 2 - 3 } & Mean & SD & & Mean & SD & \\
\hline AC (OU) & 8.5 & 3.4 & & 7.6 & 3.0 & $<0.0001$ \\
NPC & 13.0 & 5.0 & & 11.0 & 4.7 & $<0.0001$ \\
\hline
\end{tabular}

Abbreviations: AC, amplitude of accommodation; OU, both eyes; NPC, near point of convergence (cm); D, diopters; SD, standard deviation.

Table 4 Summary of horizontal and vertical phoria measures

\begin{tabular}{llll}
\hline & $\mathbf{N}$ & Mean & SD \\
\hline Horizontal phoria & 209 & 0.92 & 3.16 \\
Vertical phoria & 20 & 0.60 & 1.35 \\
\hline
\end{tabular}

Note: Data are presented in units of prism diopters with esophoria and left hyperphoria values included as negative values and exophoria and right hyperphoria values included as positive values.

Abbreviation: SD, standard deviation. have been reported with the use of computers and other digital devices, aka CVS. ${ }^{7-12}$ Individuals approaching presbyopia typically own multiple digital devices and spend prolonged amounts of time using them on a daily basis. ${ }^{3}$

This observational clinical study of accommodative and vergence dysfunction resulting from digital device use and other near work was conducted to characterize the asthenopic symptoms in a large clinical population, since most recent clinical studies reported in published literature are of relatively smaller populations than the 253 subjects evaluated in this study. Such dysfunction is classified in Table 1 as accommodative insufficiency, ill-sustained accommodation, accommodative infacility, convergence insufficiency, and convergence excess. In this study of 30 to 40 -year-old soft contact lens wearers with asthenopia, ill-sustained accommodation, which is characterized by a normal AC but fatigue with repeated accommodative stimulation, ${ }^{31}$ was the most common primary diagnosis (Figure 1). While illsustained accommodation in this age group while viewing digital technology is not surprising, it is not well discussed in published academic literature, and this may be the first study to document the high incidence of such dysfunction in early-presbyopes.

NPC in the present study $(13.0 \pm 5.0 \mathrm{~cm}$ push up/ $11.0 \pm 4.7$ $\mathrm{cm}$ push down) was greater than that reported previously as measured using a 6/12 single target on a Gulden fixation stick $\left(8.30 \pm 3.9 \mathrm{~cm}\right.$ push up in a 30 to 39 -year-old population). ${ }^{28}$ Both of these populations presented NPC greater than those of a single population of 100 individuals in which NPC was measured annually beginning in the 1970 s for 20 consecutive years before common use of digital devices $(6.3 \pm 0.8 \mathrm{~cm}$ at 18-22 years of age, compared with $6.8 \pm 1.3 \mathrm{~cm}$ at $34-38$ years of age)..$^{30}$

The mean phoria in the present study was exophoria, with low hyperphoria reported in a subset of the study cohort. Measured values (Table 4) were within the $0.78-2.33$ range reported by Collier and Rosenfield, ${ }^{20}$ who found decreased CVS symptoms in patients with low amounts of exophoria compared with zero phoria. However, near vision fatigue has also been associated with greater exo-fixation disparity. ${ }^{33}$ As phoria values measured in this study were in the normal range, it is apparent that the accommodation system rather than vergence system is the primary driver of asthenopia in the present study population.

Changes in AC during aging are understood in presbyopia. ${ }^{24}$ To quantitate accommodative changes during aging, Hofstetter analyzed historical data published in the mid-19th ${ }^{21}$ and early 20 th $^{23}$ centuries to develop formulas to 




Figure I Primary diagnosis for asthenopic symptoms among adults aged 30-40 years.

predict minimum, probable, and maximum AC. ${ }^{22}$ Noteworthy is that the historical data were collected before common electric lighting, decades before Hofstetter's analysis, before television became commonplace, and over a century before the current digital device age.

Measured $\mathrm{AC}$ values in the present study population were better than the HF predicted values $(6.23 \pm 0.80 \mathrm{D})$, with average push up/push down values of 8.04 $\pm 3.09 \mathrm{D}$ (Table 2). In comparison, Spierer and Hefetz measured lower AC of 5.5 $\pm 1.5 \mathrm{D}$ in a population of 18 to 22-year-old subjects. ${ }^{30}$ Win-Hall and Glasser measured a lower average $\mathrm{AC}$ of $4.76 \pm 1.32 \mathrm{D}$, with a range of 3.33-8.59 D in a study of 15 pre-presbyopic subjects aged $38-49$ years. ${ }^{34}$ The WinHall and Glasser study measured accommodation using both WR-5100K open-field autorefractor and iTrace aberrometer instruments at a single study site. Data reported in the present study were collected from 253 subjects by 25 investigators, each using the same standardized technique employing an RAF gauge and metronome to regulate movement of the target. Differences between the studies might be attributed to the differences in the respective age groups and likely also reflect differences in study design, technique, and sample size. It should be noted that digital display use pervasive in today's society was but a concept during the time of Spierer and Hefetz's study and had just begun to be widely adopted at the time of Win-Hall and Glasser's study.

While differences between study protocols may in part explain differences between study results, HF itself may not accurately predict $\mathrm{AC}$ values in the pre-presbyopic age group. The formula is based upon analysis of historical data measured in subjects of all ages, including children, younger adults, pre-presbyopic adults, and presbyopic adults. A recent clinical study suggests that HF inaccurately predicts AC values in children, ${ }^{35}$ which implies that Hofstetter should have excluded measurements taken in children when calculating the constants in his formula. We speculate that the formula might make more accurate predictions if different sets of constants are calculated for different age groups (young child, youth child, young adult, pre-presbyopic adult, and presbyopic adult).

Hofstetter's own studies of convergence ${ }^{36}$ were conducted during the nascent golden age of (analog) television. The effects of black and white versus color and analog versus digital images upon accommodation are beyond the scope of this study but may be important when comparing studies from different eras and may in part explain the differences between measured data and HF predictions.

Another marked difference between eras that may affect the decline in accommodation is life expectancy. The average life expectancy in the United States was 47.3 years in 1900 , compared with 68.2 years in 1950 and 77.9 years in $2007 . .^{37}$ The disparity between results of the present study and Hofstetter's prediction might also imply that age-related patterns of lost accommodative function changed over the years as life expectancy increased, with those born at the turn of the last century facing presbyopia shortly before death and those 
born today living nearly as long with presbyopia as without. Alternatively, the HF has never been validated rigorously by clinical trial and may be inherently less accurate than commonly assumed.

Accommodation values in the present study fell within the higher range reported by Cheng et al, perhaps due to technique differences, or to the slightly older population in that study. ${ }^{38}$ Push up values in the present study were better than push down values, in agreement with Antona et al. ${ }^{39}$ Others have also reported a difference between push up and push down measurements; a suggested compromise has been to average the push up and push down values to account for differences in the techniques. ${ }^{40}$

This large observational study supports the hypothesis that habitual use of modern digital devices and other near work exacerbates accommodative dysfunction in pre- and early-presbyopes wearing contact lenses. However, as the study was observational and lacked control groups, further clinical evaluation is needed to confirm this finding, as well as to elucidate if the observed effects can be attributed primarily to one or two dominant variables (eg, degree of myopia, particulars of contact lenses wear, duration of screen use, etc).

Increased computer usage and resulting symptoms motivated development of potential treatments and therapies, such as vision therapy or exercises to relax the accommodative response and relieve symptoms of eyestrain. ${ }^{41}$ The ergonomics of work environments have also been evaluated to determine whether better working conditions, such as improved lighting or screen filters, might be helpful. ${ }^{42,43}$ In addition, refractive lens options such as computer vision or progressive glasses, antiglare-treated lenses, and filtered lenses, as well as multifocal contact lenses may help relieve symptoms of asthenopia. ${ }^{2,44}$ Glasses designed to stimulate blinking during computer use have also been reported. ${ }^{45}$ Under some conditions, the type of display and font size of the handheld device can be adjusted to provide a better viewing experience. ${ }^{46}$ Physiological factors such as dry eye and blink response also contribute to the symptoms and are considered potential areas of treatment. ${ }^{10}$

Visual displays must also be considered in the context of sensitivity to blur. Some display characteristics can affect the amount of rendered image blur, which plays a role in accommodation as it increases at larger or smaller depths, thereby contributing to the depth of field. Blur also serves as a cue for accommodation; thus, when there are large fluctuations in accommodation, discomfort can arise from visual fatigue. ${ }^{47}$

Optical blur has also been studied relative to aberrations, as both low and high order aberrations result in blurred images formed by the eye. ${ }^{48}$ Some studies suggest that controlling aberrations might aid the accommodation system. ${ }^{38,49-52}$ For example, Cheng et al reported that accommodation was accompanied by concurrent changes in aberration, with spherical aberration (SA) showing the greatest change with accommodation. ${ }^{38}$ Additional studies are needed to understand the implications of SA correction in pre- and early-presbyopia, and to investigate the optimal amount of $\mathrm{SA}$ in this age group.

As technology demands on vision continue to increase, the accommodative burden and resulting symptoms will increase and become of greater clinical interest. Surveys show that devices with ever-decreasing screen sizes are becoming increasingly popular across age groups, and as early as childhood. ${ }^{1,2}$ Understanding the influence of these technologies on the accommodative burden can aid in the development of treatments, therapies, and refractive lens options. As reported in the present study, ill-sustained accommodation was the most frequent primary diagnosis among this 30 to 40-year-old population. These outcomes underscore the importance of providing a comprehensive binocular vision assessment in current patient populations, and assessing near vision demands relative to near work and multiple digital platforms such as smart phones, tablets, e-readers, and computers. Further clinical studies to determine if accommodative dysfunction during contact lens wear observed in this study is a consequence of digital display use or near work, a concomitant effect of other causes or symptoms of CVS, or something else entirely, are warranted.

\section{Conclusion}

Demands on the binocular visual system are certain to increase as the use of digital media increases and the size of digital screens decreases. The use of digital media by pre- and early-presbyopic populations has grown with the introduction of new devices. Based upon the standardized assessment of accommodation and vergence, ill-sustained accommodation was the most common diagnosis among this relatively large population of 30 to 40 -year-old myopic, adapted, soft contact lens wearing subjects with symptoms of asthenopia, while vergence dysfunction was less prevalent. As near vision demands of digital media increase, the importance of comprehensive binocular vision assessment also increases.

\section{Acknowledgments}

The authors would like to thank Suzie Webster for her contributions to the manuscript. 
The abstract of this paper was presented at the Annual Meeting of the American Academy of Optometry held at San Francisco, CA, USA on November 17-20, 2010 as a poster presentation (program number 105221) with interim findings. The poster's abstract was published online and is available for download at https://www.aaopt.org/detail/knowledgebase-article/evaluation-binocular-function-among-preearlypresbyopes-asthenopia.

\section{Disclosure}

William Reindel and Marjorie Rah are employees of Bausch \& Lomb Inc; Lening Zhang was an employee of Bausch \& Lomb Inc at the time of the study; and Joseph Chinn is a paid consultant to Bausch \& Lomb Inc. The authors report no other conflicts of interest in this work.

\section{References}

1. Pewinternet.org [homepage on the Internet]. U.S. smartphone use in 2015. Washington, DC: Pew Research Center; 2015 [updated April 1, 2015; cited February 1, 2017]. Available from: http://www.pewinternet. org/2015/04/01/us-smartphone-use-in-2015/. Accessed September 1, 2017.

2. The Vision Council. Overexposed: the digital device dilemma. 2016 Digital eye strain report. Alexandria, VA: The Vision Council; 2016 [cited February 1, 2017]. Available from: https://visionimpactinstitute. org/wp-content/uploads/2016/03/2016EyeStrain_Report_WEB.pdf. Accessed November 27, 2017.

3. The Vision Council. Hindsight is 20/20/20: protect your eyes from digital devices. 2015 Digital eye strain report. Alexandria, VA: The Vision Council; 2015 [cited February 1, 2017]. Available from: http://www. pcom.ph/sites/default/files/downloads/vc_digitaleyestrain_report2015. pdf. Accessed November 27, 2017.

4. Eichenbaum JW. Computers and eyestrain. J Ophthalmic Nurs Technol. 1996;15(1):23-26.

5. Tsubota K, Nakamori K. Dry eyes and video display terminals. N Engl J Med. 1993;328(8):584.

6. Patel S, Henderson R, Bradley L, Galloway B, Hunter L. Effect of visual display unit use on blink rate and tear stability. Optom Vis Sci. 1991;68(11):888-892.

7. Sheedy J. What's in a name: "computer vision syndrome "? Optometry. 2002;73(7):399-402.

8. American Optometric Association. The effects of computer use on eye health and vision. St Louis, MO: American Optometric Association; 1997 [cited February 1, 2017]. Available from: http://www.aoa. org/Documents/optometrists/effects-of-computer-use.pdf. Accessed September 1, 2017.

9. Von Stroh R. Computer vision syndrome. Occup Health Saf. 1993;62(10): $62-66$.

10. Rosenfield M. Computer vision syndrome: a review of ocular causes and potential treatments. Ophthalmic Physiol Opt. 2011;31(5): 502-515.

11. Gowrisankaran S, Sheedy JE. Computer vision syndrome: a review. Work. 2015;52(2):303-314.

12. Blehm C, Vishnu S, Khattak A, Mitra S, Yee RW. Computer vision syndrome: a review. Surv Ophthalmol. 2005;50(3):253-262.

13. Wolkoff P, Nøjgaard JK, Troiano P, Piccoli B. Eye complaints in the office environment: precorneal tear film integrity influenced by eye blinking efficiency. Occup Environ Med. 2005;62(1):4-12.

14. Cardona G, García C, Serés C, Vilaseca M, Gispets J. Blink rate, blink amplitude, and tear film integrity during dynamic visual display terminal tasks. Curr Eye Res. 2011;36(3):190-197.
15. Gowrisankaran S, Nahar NK, Hayes JR, Sheedy JE. Asthenopia and blink rate under visual and cognitive loads. Optom Vis Sci. 2012;89(1):97-110.

16. Bentivoglio AR, Bressman SB, Cassetta E, Carretta D, Tonali P, Albanese A. Analysis of blink rate patterns in normal subjects. Mov Disord. 1997;12(6):1028-1034.

17. Schafer J, Steffen R, Reindel W, Chinn J. Evaluation of surface water characteristics of novel daily disposable contact lens materials, using refractive index shifts after wear. Clin Ophthalmol. 2015;9:1973-1979.

18. Tauste A, Ronda E, Molina MJ, Seguí M. Effect of contact lens use on computer vision syndrome. Ophthalmic Physiol Opt. 2016;36(2):112-119.

19. Porcar E, Pons AM, Lorente A. Visual and ocular effects from the use of flat-panel displays. Int J Ophthalmol. 2016;9(6):881-885.

20. Collier JD, Rosenfield M. Accommodation and convergence during sustained computer work. Optometry. 2011;82(7):434-440.

21. Donders FC, Moore WD. On the Anomalies of Accommodation and Refraction of the Eye: With a Preliminary Essay on Physiological Dioptrics. London: New Sydenham Society; 1864.

22. Hofstetter HW. The relationship of proximal convergence to fusional and accommodative convergence. Useful age-amplitude formula. Optom World. 1950;38:42-45.

23. Duane A. Normal values of the accommodation at all ages. JAMA. 1912;59(12):1010-1013.

24. Pointer JS, Gilmartin B. Patterns of refractive change in myopic subjects during the incipient phase of presbyopia: a preliminary study. Ophthalmic Physiol Opt. 2011;31(5):487-493.

25. Jaschinski W, König M, Mekontso TM, Ohlendorf A, Welscher M. Computer vision syndrome in presbyopia and beginning presbyopia: effects of spectacle lens type. Clin Exp Optom. 2015;98(3):228-233.

26. Vedamurthy I, Harrison WW, Liu Y, Cox I, Schor CM. The influence of first near-spectacle reading correction on accommodation and its interaction with convergence. Invest Ophthalmol Vis Sci. 2009;50(9):4215-4222.

27. Yekta AA, Pickwell LD, Jenkins TC. Binocular vision, age and symptoms. Ophthalmic Physiol Opt. 1989;9(2):115-120.

28. Ostadimoghaddam H, Hashemi H, Nabovati P, Yekta A, Khabazkhoob $\mathrm{M}$. The distribution of near point of convergence and its association with age, gender and refractive error: a population-based study. Clin Exp Optom. 2017;100(3):255-259.

29. Siderov J, Chiu SC, Waugh SJ. Differences in the near point of convergence with target type. Ophthalmic Physiol Opt. 2001;21(5):356-360.

30. Spierer A, Hefetz L. Normal heterophoric changes: 20 years' follow-up. Graefes Arch Clin Exp Ophthalmol. 1997;235(6):345-348.

31. Cooper JS, Burns CR, Cotter SA, Daum KM, Griffin JR, Scheiman MM. Optometric clinical practice guideline. Care of the patient with accommodative and vergence dysfunction. St Louis, MO: American Optometric Association; 1998. Revised 2010 [cited February 1, 2017]. Available from: http://www.aoa.org/documents/optometrists/CPG-18. pdf. Accessed September 1, 2017.

32. Cristarella MC. Visual functions of the elderly. Am J Occup Ther. 1977;31(7):432-440.

33. Jaschinski W. The proximity-fixation-disparity curve and the preferred viewing distance at a visual display as an indicator of near vision fatigue. Optom Vis Sci. 2002;79(3):158-169.

34. Win-Hall DM, Glasser A. Objective accommodation measurements in prepresbyopic eyes using an autorefractor and an aberrometer. $J$ Cataract Refract Surg. 2008;34(5):774-784.

35. Hashemi H, Nabovati P, Khabazkhoob M, Yekta A, Emamian M, Fotouhi A. Does Hofstetter's equation predict the real amplitude of accommodation in children? Clin Exp Optom. Epub 2017 May 17.

36. Hofstetter HW. The relationship of proximal convergence to fusional and accommodative convergence. Am J Optom Arch Am Acad Optom. 1951;28(6):300-308.

37. Life expectancy at birth, at age 65 , and at age 75 , by sex, race, and Hispanic origin: United States, selected years 1900-2010. Atlanta, GA: Center for Disease Control/National Center for Health Statistics/ Office of Analysis and Epidemiology; 2010 [cited July 1, 2017]. Available from: https://www.cdc.gov/nchs/data/hus/2010/022.pdf. Accessed September 1, 2017. 
38. Cheng H, Barnett JK, Vilupuru AS, et al. A population study on changes in wave aberrations with accommodation. J Vis. 2004;4(4):272-280.

39. Antona B, Barrra F, Barrio A, Gonzalez E, Sanchez I. Repeatability intraexaminer and agreement in amplitude of accommodation measurements. Graefes Arch Clin Exp Ophthalmol. 2009;247(1):121-127.

40. Rosenfield M, Logan N, Edwards K, editors. Optometry: Science, Techniques, and Clinical Management. 2nd ed. Edinburgh: Butterworth-Heinemann-Elsevier; 2009.

41. Omori M, Watanabe T, Takai J. An attempt at preventing asthenopia among VDT workers. Int J Occup Saf Ergon. 2003;9(4):453-462.

42. Mutti DO, Zadnick K. Is computer use a risk factor for myopia? $J A m$ Optom Assoc. 1996;67(9):521-530.

43. Sheedy JE. The bottom line on fixing computer-related vision and eye problems. J Am Optom Assoc. 1996;67(9):512-517.

44. Aoa.org [homepage on the Internet]. 5 tips for multifocal contact lens success. St Louis, MO: American Optometric Association; 2016 [updated February 9, 2016; cited February 1, 2017]. Available from: http://www.aoa.org/news/clinical-eye-care/5-tips-for-multifocalcontact-lens-success?sso=y. Accessed September 1, 2017.

45. Ang CK, Mohidin N, Chung KM. Effects of wink glass on blink rate, nibut and ocular surface symptoms during visual display unit use. $\mathrm{Curr}$ Eye Res. 2014;39(9):879-884.
46. Gill K, Mao A, Powell AM, Sheidow T. Digital reader vs print media: the role of digital technology in reading accuracy in age-related macular degeneration. Eye (Lond). 2013;27(5):639-643.

47. O'Hare L, Hibbard PB. Visual discomfort and blur. J Vis. 2013; 13(5):7.

48. Sawides L, Dorronsoro C, Haun AM, Peli E, Marcos S. Using pattern classification to measure adaptation to the orientation of high order aberrations. PLoS One. 2013;8(8):e70856.

49. Allen PM, Rakhakrishman H, Rae S, et al. Aberration control and vision training as an effective means of improving accommodation in individuals with myopia. Invest Ophthalmol Vis Sci. 2009;50(11):5120-5129.

50. Khalifa MA, Allam WA, Khalifa AM. Improving near vision in presbyopic eyes by selective treatment of high-order aberrations. Clin Ophthalmol. 2011;5:1525-1530.

51. Gambra E, Sawides L, Dorronsoro C, Marcos S. Accommodative lag and fluctuations when optical aberrations are manipulated. $J$ Vis. 2009;9(6):4.

52. Theagarayan B, Radhakrishnan H, Allen PM, Calver RI, Rae SM, O'Leary DJ. The effect of altering spherical aberration on the static accommodative response. Ophthalmic Physiol Opt. 2009;29(1): $65-71$.
Clinical Optometry

\section{Publish your work in this journal}

Clinical Optometry is an international, peer-reviewed, open access journa publishing original research, basic science, clinical and epidemiologica studies, reviews and evaluations on clinical optometry. All aspects of patient care are addressed within the journal as well as the practice of optometry including economic and business analyses. Basic and clinical

Submit your manuscript here: https://www.dovepress.com/clinical-optometry-journal
Dovepress

research papers are published that cover all aspects of optics, refraction and its application to the theory and practice of optometry. The manuscript management system is completely online and includes a very quick and fair peer-review system, which is all easy to use. Visit http://www.dovepress. com/testimonials.php to read real quotes from published authors. 